\title{
USER'S GUIDE FOR FINDIF AT SACLANTCEN
}

\author{
Ralph A.Stephen \\ Department of Geology and Geophysics \\ Woods Hole Oceanographic Institution \\ Woods Hole, MA 02543
}

May 1992

This work was carried out under ONR Contract \#N00014-89-J-1012 and

under ONR Grant \#N0001490J1541 


\section{Index}

Index

page number

1

1. Introduction 3

2. Model Description and the Parameter File 6

3. The Programs

9

3a) The Preprocessor - SCNTPREP 9

3b) Generating the Parameter Matrices - *BNY 9

3c) The finite difference calculations - SCNTDIF 11

3d) Use on the VAX9000 12

3e) Summary of Subroutines and 'INCLUDE' Files 13

4. Running SCNTDIF 14

5. Examples 17

5a) Andrea Caiti 17

5b) Tuncay Akal $\quad 18$

5c) Jens Hovem 18

5d) Dale Ellis $\quad 18$

5e) Dan Lott 18

5f) John Preston 19

6. Computation Time 19

$\begin{array}{ll}\text { 7. Recommended Modifications } & 19\end{array}$

$\begin{array}{lr}\text { 8. References } & 20\end{array}$ 


\section{FIGURES}

FIGURE 1: Layout of the Finite Difference Grid

page number

FIGURE 2: Source Waveforms and Amplitude Spectra for Pulse Sources

FIGURE 3: An example of a parameter file, CAI04.PAR

FIGURE 4: The command file for creating an executable of

SCNTPREP on the VAX 8600/900

FIGURE 5: The command file for creating an executable of CAI03BNY on the VAX 8600/9000 10

FIGURE 6: Some examples of *BNY files.

FIGURE 7: The command file for creating an executable of SCNTDIF for the FPS 264

FIGURE 8: The command file for creating an executable of SCNTDIF for the VAX 9000

FIGURE 9: $\quad$ MODEL CAI04 15

FIGURE 10: $\quad$ Example of the CAI04.BCH file 16

FIGURE C-1: $\quad 21$

FIGURE C-2: CAI03BNY.FOR 22

FIGURE C-3A: $\quad 25$

FIGURE C-3B: $\quad 26$

FIGURE C-3C: 27

FIGURE C-4A: $\quad 28$

FIGURE C-4B: $\quad 29$

FIGURE C-4C: $\quad 30$

FIGURE C-5A: $\quad 31$

FIGURE C-5B: $\quad 32$

TABLE 1: Typical Run Times for the SCNTDIF code on the

VAX 8600/FPS264 at SACLANTEN. 
FINDIF solves the elastic wave equation for a line source in two dimensions by the finite difference method (Virieux,1986; Stephen,1988b). The solution is carried out in the time domain for either pulse or $\mathrm{CW}$ sources. Arbitrary distributions of compressional velocity, shear velocity and density (including fluids and solids) can be defined on the finite difference grid. All compressional waves, shear waves, interface waves and evanescent waves are included as are all conversions between wave types. Multiple forward and backward scattering is automatically treated. FINDIF was developed at Woods Hole Oceanographic Institution.

FINDIF has been applied to a wide variety of problems in ocean seismo-acoustics. Early work verified the agreement between finite difference and reflectivity results for laterally homogeneous seafloor models with gradients in elastic properties (Stephen,1983; Hunt and Stephen, 1986). (The reflectivity method is a wavenumber integral approach like SAFARI.) The code has been used to study the effects of range dependent environment on deep sea borehole seismic data in the Gulf of California (Stephen,1984) and the equatorial, East Pacific (Stephen,1988a). A modified version of the code has been applied to acoustic well logging problems in horizontally stratified media (Stephen et al, 1985). The code was also used for a series of benchmark wedge models defined by the Acoustical Society of America and the results compared quite favourably with other techniques (Stephen,1990).

Stephen (1988b) summmarizes the evolution of finite difference methods as applied to seafloor interaction problems. The template used in the FINDIF code is based on a formulation by Virieux (1986); the source is introduced using a method described by Nicoletis (1981); and the absorbing boundaries are treated using the 'telegraph equation' approach described by Levander(1985).

There are a number of versions of FINDIF which are specifically tailored to address particular problems. The version of FINDIF which is running at SACLANTCEN is called SCNTDIF and it is tailored to study shallow water propagation problems over range dependent, elastic bottoms (ie. bottoms with two-dimensionally varying compressional and shear velocity and density, but without attenuation). In this version the source is always a compressional point source in the water column and the problem is symmetrical in range about the source.

SCNTDIF is run in three stages. The first stage is a preprocessor, SCNTPREP, which creates 'COMMON' blocks with the correct dimensions for a given problem. These 'COMMON' blocks are then introduced into subsequent programs by 'INCLUDE' statements. Input is specified through a parameter file, MDLID.PAR. (MDLID is any user specified model identifier.) The second stage requires defining the compressional and shear wave speeds and density on the finite difference grid. This is usually done by a user written FORTRAN program. Some examples, called CAI01BNY.FOR, CAI02BNY.FOR, AKA01BNY.FOR, etc are discussed below. The third stage is to actually compute the wave field using FINDIF. Results are output as snapshots (the complete two dimensional wavefield at an instant of time) and as time series (time histories of pressure or displacement) at particular locations in the model. (There is a post-processor, CONVEL, to convert displacement time series to velocity.)

At SACLANTCEN, SCNTDIF is currently configured to run on the FPS260 with the VAX8600/VAX9000 host or on the VAX8600/9000 itself. This user's guide describes the code installed on all three computers at SACLANTCEN and describes some examples. 
FIGURE 1: Layout of the Finite Difference Grid

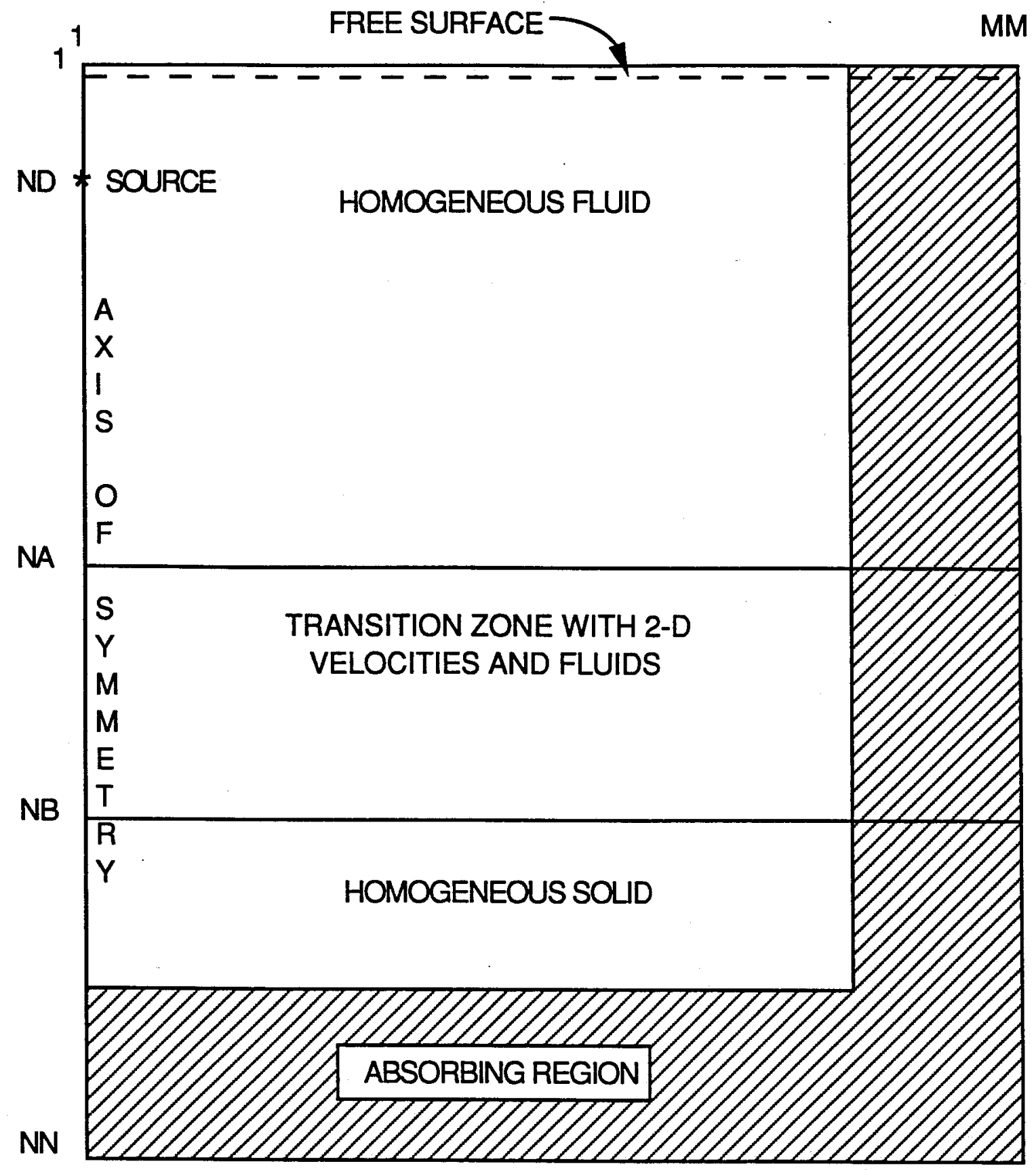


FIGURE 2: Source Waveforms and Amplitude Spectra for Pulse Sources

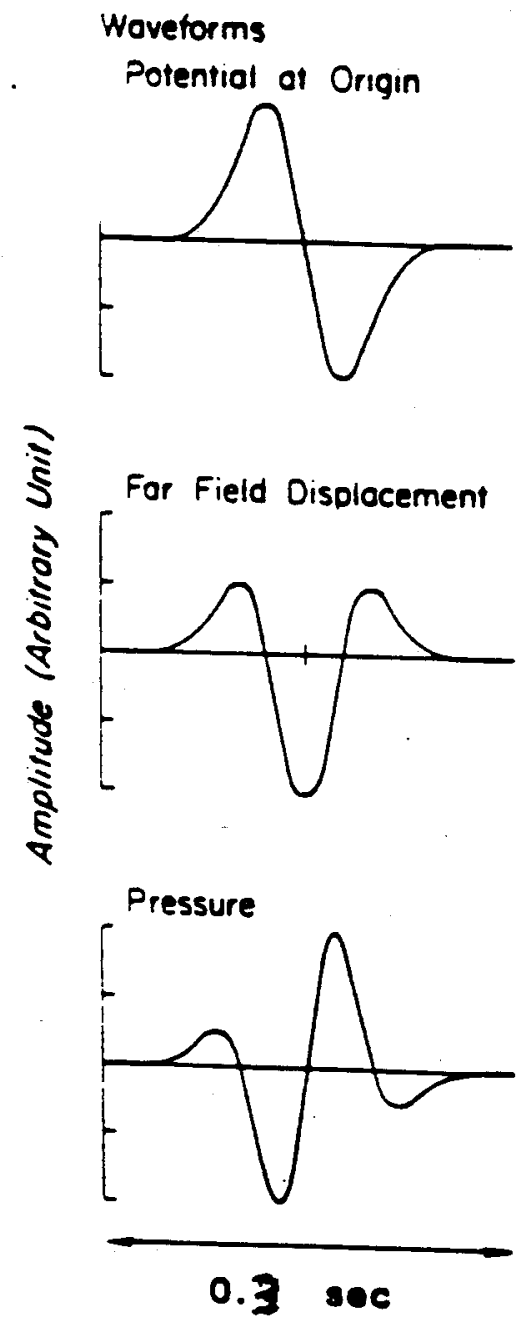

Amplifude Spectro
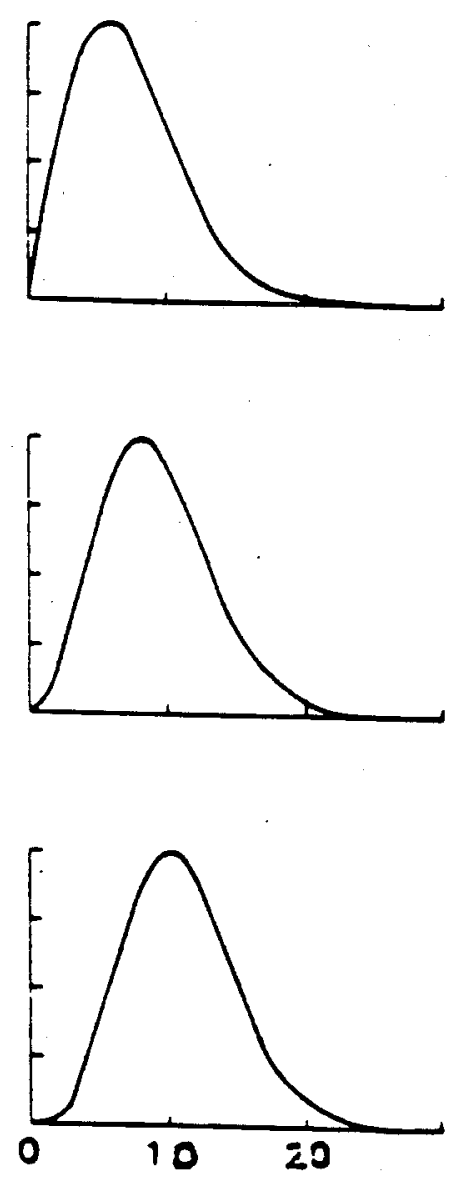

Frequency $(\mathrm{i}+2)$ 


\section{Model Description and the Parameter File}

Figure 1 represents a cross section vertically through the ocean and seafloor as used in SCNTDIF. The model assumes a Cartesian coordinate system so that features on the grid extend into and out of the page. The top edge is a free surface, the left edge is an axis of symmetry, and the right and bottom edges are absorbing regions. The (line) source is located on the axis of symmetry. In order to improve computational performance the grid is divided into three regions. The top region represents a homogeneous water column. In the middle region, or transition zone, an arbitrary distribution of liquids and solids in two dimensions is treated. This typically represents the seafloor with either surface roughness or volume heterogeneities. If desired the top region can have zero thickness, so that two dimensional variability can go up to the free surface. In this case vertical velocity gradients and/or two dimensional variability in the water column can be treated. The bottom region represents a homogeneous solid and serves to carry energy away from the scattering region where it can be attenuated without contaminating the desired solution.

The time dependence of the source can either be a pulse (in pressure, the third derivative of a Gaussian profile) or a continuous wave, single frequency $(\mathrm{CW})$ signal. The pulse waveforms are shown in Figure 2 and are described in Appendix E of Stephen et al (1985). For a given peak frequency the bandwidth is automatically prescribed. For example, for a $10 \mathrm{~Hz}$ pulse in pressure, the lower and upper half power points are $6.82 \mathrm{~Hz}$ and $13.56 \mathrm{~Hz}$, respectively.

The absorbing boundaries are treated by applying the telegraph equation in a region adjacent to the boundary. The attenuation coefficient profile and the thickness of the absorbing region have been chosen by trial and error to ensure that reflections from the absorbing region will be negligible for typical seafloor models. In SCNTDIF the width of the absorbing boundary is fixed at 90 grid points.

Wave propagation is scale independent. For example, a $10 \mathrm{~Hz}$ problem for a $5 \mathrm{sec}$ duration in a model $10 \mathrm{~km}$ long with a grid interval of $10 \mathrm{~m}$ is equivalent to a $1 \mathrm{KHz}$ problem for a duration of $50 \mathrm{msec}$ in a model $100 \mathrm{~m}$ long with a grid interval of $100 \mathrm{~cm}$. Models are equivalent provided that all range, depth and time parameters are multiplied (or divided) by the same factor. However, for convenient use of the program in shallow water acoustics studies, SCNTDIF assumes that all distances are in kilometers and that all times are in seconds (frequencies in Hertz). 
FIGURE 3: An example of a parameter file, CAI04.PAR

CAIO4 - TEST MODEL FOR ANDREA - WITH 3 LAYERS

CAI0 4

$1, \quad 1, \quad 0, \quad-2, \quad 1, \quad 0, \quad 0, \quad 1$

$601,401,20001,1,0.0001,0.0005,0.0005$

$1,20001,1, \quad 601,132, \quad 132$

$8, \quad 10, \quad 10,20005,200$

$1.5,0.0, \quad 1.0, \quad 1.7,0.18,1.2,131,153,1.7,0.18,1.2$

$121,1, \quad 11, \quad 2$

11, 65746.0, 0.0

An example of a parameter file is shown in Figure 3. It is a free formatted ASCII file. A description of the lines follows.

Line 1 - LABEL

Label up to 80 characters long describing the model.

Line 2 - FILEID

This is a five character model identifier used to identify all outputs from

SCNTDIF.

Line 3 - IRECT, IDENS, IFLAT, IKELLY, IEXPL, IVERT, ITRAN, ISORB

IRECT $=1$ for Cartesian coordinates.

IDENS $=1$ for density variations.

IFLAT $\quad=0$ for a water layer beneath a free surface and over an elastic halfspace;

= 1 for the water layer beneath a plane of symmetry;

$=-2$ for intrinsic attenuation (not yet implemented).

IKELLY $=-1$ for Gaussian source function applied as a point force on the seafloor $(\mathrm{ND}=\mathrm{NA}+1)$ (implemented on the FPS version only);

$=-2$ for Gaussian source function applied as a point source in the water column;

$=0$ or -3 for the Schmitt broadband source function applied as a point source in the water column (implemented on the FPS version only).

IEXPL $=1$ for explicit finite difference formulation.

IVERT $=0$ for timeseries output of pressure, verticaldisplacement, and horizontal displacement;

$=1$ for time series output of vertical displacement only;

= 2 for time series output of horizontal displacement only;

$=3$ for time series output of pressure only.

ITRAN $=0$ for heterogeneous formulation in transition region.

ISORB $=1$ for absorbing boundaries. 
Line 4 - MM,NN,KK,KSTRT,DELT,DELR,DELZ

MM - Number of points in range;

NN - Number of points in depth;

$\mathrm{KK} \quad-$ Number of points in time;

KSTRT $=1$ is the starting increment in time

DELT - Time increment (sec);

DELR - Range increment $(\mathrm{km})$

DELZ - Depth increment $(\mathrm{km})$ (DELZ=DELR).

Line 5 - KOUTST,KOUTEN,MOUTST,MOUTEN,NOUTST,NOUTEN

KOUTST - Initial output time index for time series;

KOUTEN - Final output time index for time series;

MOUTST - Initial output range index for time series;

MOUTEN - Final output range index for time series;

NOUTST - Initial output depth index for time series;

NOUTEN - Final output depth index for time series.

Line 6 - KINC,MINC,NINC,KMARK,KMINC

KINC - Time index increment for time series.

MINC - Range index increment for time series.

NINC - Depth index increment for time series.

KMARK - Time index of first snapshot (If KMARK is greater than KK, no snapshots are output);

KMINC - Time index increment for snapshots.

Line 7 - VP1,VS1,RO1,VP2,VS2,RO2,NA,NB,VPT,VST,ROT

VP1 - P-wave velocity in upper homogeneous layer (forNA.GT.2);

VS1 - P-wave velocity at the surface (for NA.LE.2) $(\mathrm{km} / \mathrm{sec})$;

VS1 - S-wave velocity in upper homogeneous layer (for NA.GT.2);

RO1 - Density in upper homogeneous layer (for NA.GT.2);

VP2 - Density at the surface (for NA.LE.2)(gm/cc);

VS2 - S-wave velocity in lower homogeneous layer $(\mathrm{km} / \mathrm{sec})$;

$\mathrm{RO} 2$ - Density in lower homogeneous layer $(\mathrm{gm} / \mathrm{cc})$.

NA - Depth index for the top of the 'transition zone', the region of full elastic two-dimensional variability;

NB - Depth index for the bottom of the 'transition zone'.

VPT - Dummy P-wave velocity $(\mathrm{km} / \mathrm{sec})$;

VST - Dummy S-wave velocity $(\mathrm{km} / \mathrm{sec})$;

ROT - Dummy density $(\mathrm{gm} / \mathrm{cc})$.

Line 8 - ND,MD,NSW, MSW

ND - Depth index of source

$\mathrm{MD} \quad=1$ Range index of source

NSW - Dummy value

MSW $\quad=2$ Gives source resolution.

Line 9 - NSORCE,PLSWID,TSWAVE

NSORCE - Dummy value

PLSWID - Duration parameter for Gaussian source pulse. (PLSWID is 6.574 times the square of the peak frequency in pressure in Hertz)

TSWAVE - Time shift parameter (seconds) for the source. (If TSWAVE equals zero, the code automatically chooses an appropriate value for the source type and frequency.) 


\section{The Programs}

(Sections a-c describe the code implemented using the FPS264. Section d describes the code using the VAX9000.)

3a) The Preprocessor - SCNTPREP

The source code for SCNTPREP resides in PR19_DISK:[STEPHEN.BENCH.VAX.PRP]. SCNTPREP reads the MDLID.PAR file and creates a file,SCOMFD8.FOR, which contains 'COMMON' blocks of the arrays necessary to run the other two stages. A command file for creating an executable of SCNTPREP is shown in Figure 4. SCNTPREP requires the 'INCLUDE' file, SMODPAR.FOR. It uses subroutines SRDMPAR, SOPNCOM, DATIM and SLOGOUT which are described in the subroutine section below. A log file, MDLID.LG1, is also created which lists the parameters and relevant output from SCNTPREP.

Figure 4: The command file for creating an executable of SCNTPREP on the VAX8600/9000

$\$ !$

$\$ ! \quad$ Link command file for scntprep 10 May 1990

$\$ !$

$\$$ SET VERIFY

$\$$ FOR SCNTPREP.FOR

$\$$ FOR DATIM.FOR

$\$$ FOR SLOGOUT.FOR

$\$$ FOR SOPNCOM.FOR

$\$$ FOR SRDMPAR.FOR

\$ LINK SCNTPREP,DATIM,SLOGOUT,SOPNCOM,SRDMPAR

$\$$ SET NOVERIFY

3b) Generating the Parameter Matrices - *BNY

In all cases, between depth increments NA and NB and for all ranges it is necessary to specify values of compressional velocity, shear velocity and density. Fluids can be represented by setting the shear velocity to zero. This stage requires the most user intervention and can be the most fun because the user can define his own media. The code is commonly referred to as the transition zone code because it defines the grid values in the transition zone between NA and NB.

The code resides in PR19_DISK:[STEPHEN.BENCH.FPS.BNY]. *BNY reads the $M D L I D . P A R$ file. It then computes Lame's parameters and density for each grid point, extrapolating and interpolating if necessary and outputs the values to a $M D L I D . B N Y$ file for use by SCNTDIF. A command file for creating an executable of *BNY is shown in Figure 5. *BNY requires 'INCLUDE' files SMODPAR.FOR, SIOUNIT.FOR, and SCOMFD8.FOR. It uses subroutines DATIM, SLOGOUT, SRDMPAR, and SOPNCOM which are described in the subroutine section. The progress of the *BNY file is summarized in the log file, MDLID.LG2. 
Figure 5: The command file for creating an executable of CAI03BNY on the VAX8600/9000

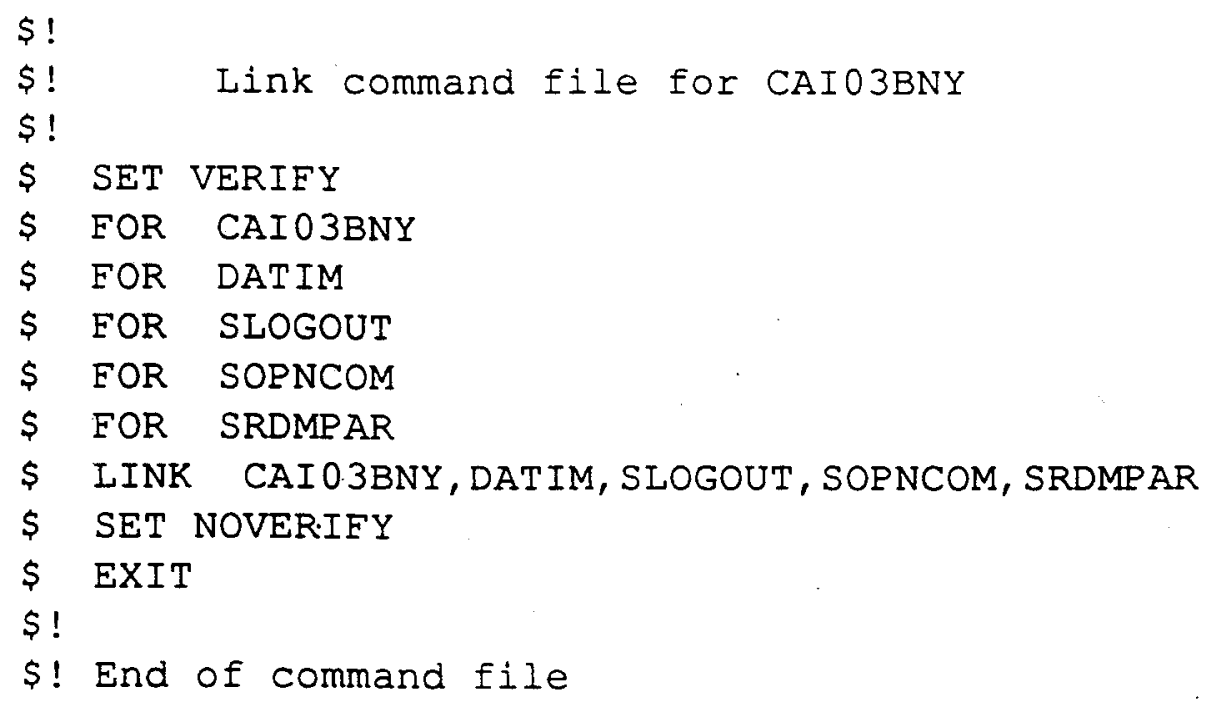

Examples of *BNY which generate a variety of standard profiles are included in PR19_DISK:[STEPHEN.BENCH.FPS.BNY]. These are summarized in Figure 6. In designing new profiles it is best to make changes to an existing code. Also note that the free surface is at grid point 2. For each model, SCNTPREP should be rerun and the *BNY program should be recompiled using the command file, to insure that the arrays in SCOMFD8.FOR have the correct dimensions.

Figure 6. Some examples of *BNY files.

CAIO1BNY - A homogeneous half space (acoustic or elastic) below a homogeneous liquid layer. (Good for testing.)

CAI03BNY - A layered elastic halfspace below a liquid layer. (This code has layer parameters corresponding to a model for Andrea (Taiti.)

AKAO1BNY - A layered elastic halfspace below a liquid layer. (This code has layer parameters corresponding to a model for Tuncay Akal.)

ELLOIBNY - A layered elastic halfspace below a liquid layer. (This code has layer parameters corresponding to a model for Dale Ellis.)

HOVO1BNY - A layered elastic halfspace below a liquid layer. (This code has layer parameters corresponding to a model for Jens Hovem.) 
3c) The finite difference calculations - SCNTDIF

SCNTDIF does the major calculations. The code resides in PR19_DISK:[STEPHEN.BENCH.FPS.DIF]. It takes parameters from the $M D L I D . P A R$ file and profiles (in 2-D) from the MDLID.BNY file and generates timeseries files (MDLID.TSV for vertical displacement, $M D L I D$.TSH for horizontal displacement, and $M D L I D . T S P$ for pressure), and snapshot files (MDLIDTTTT.DIV for compressional energy density, $M D L I D T T T T$.CRL for shear energy density, $M D L I D T T T T$.VRT for vertical displacement and $M D L I D T T T T . H R Z$ for horizontal displacemnet - TTTT is a four character field representing the time step). A command file for creating an executable of SCNTDIF is shown in Figure 7. SCNTDIF requires 'INCLUDE' files SMODPAR.FOR, SIOUNIT.FOR, SCBLCK.FOR and SCOMFD8.FOR. It uses subroutines SCNTTS9, SCNTSUB7, SFSETUP, ZSNPOUT, ZDIVCRL, ZTSOUT, TINIT, DATIM, SLOGOUT, SRDMPAR, and SOPNCOM which are described in the subroutine section. The preprocessor, SCNTPREP, should be run, and SCNTDIF recompiled for every new model to insure that correct array dimensions are being used. Results of SCNTDIF are output to the log file MDLID.LG4.

\section{FPS264}

Figure 7. The command file for creating an executable of SCNTDIF for the 
3d) Use on the VAX9000

SCNTDIF on the VAX9000 is very similar to the version run on the FPS264. Some timing and date routines work on the VAX9000 that had been disabled on the FPS264 and the file labelling works better on the VAX9000. To run SCNTDIF on the VAX9000 use the code in PR12_DISK:[AKAL.RALPH.FINDIF]. Copy all the files from this area into your own work space and edit the MDLID.PAR and FINDIF COM files for your own applications. An example of FINDIF.COM for the VAX9000 version is given in Figure 8.

Figure 8. The command file for creating an executable of SCNTDIF for the VAX9000

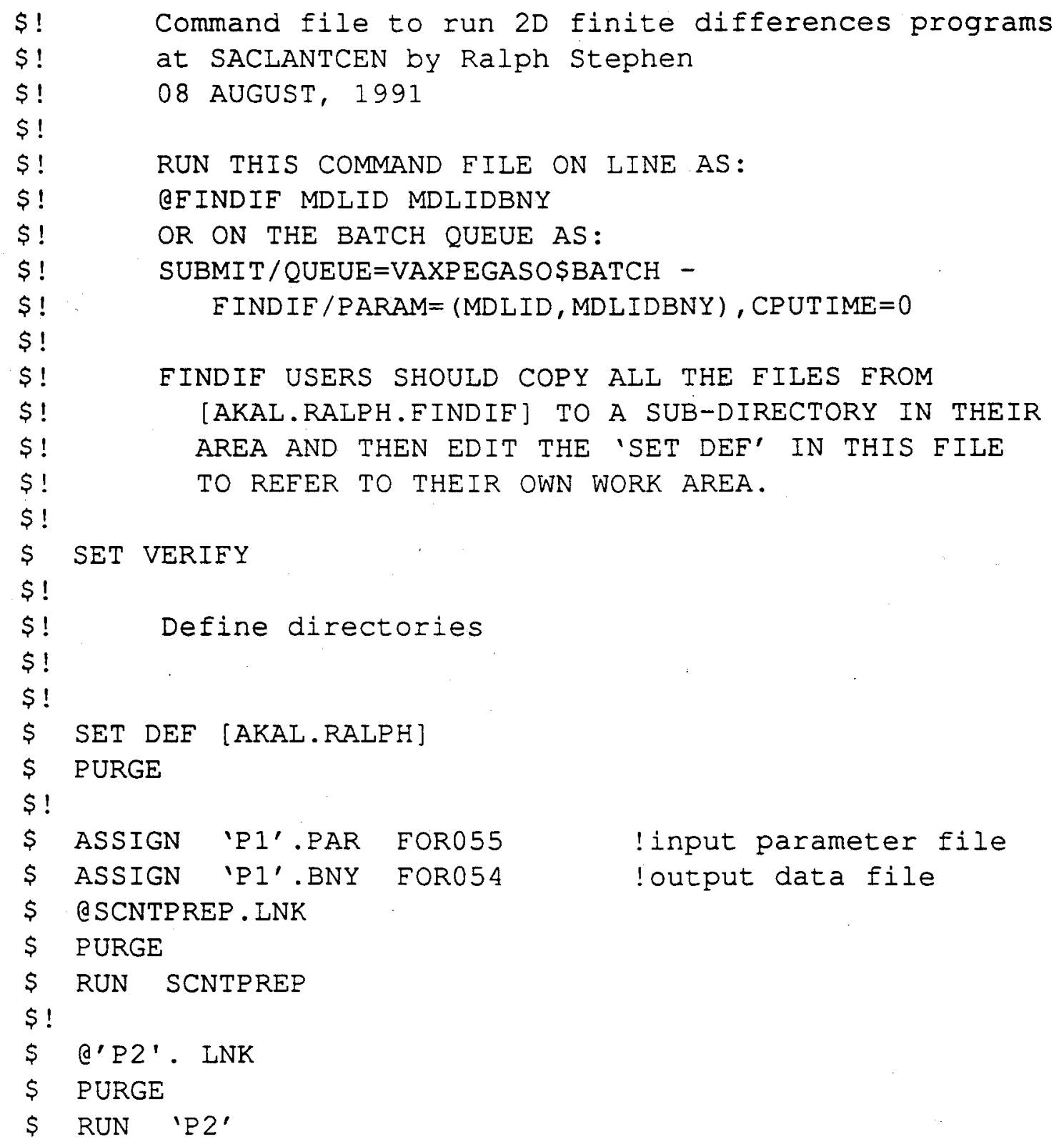

$\$ !$

$\$ !$

$\$$ Q'P2'. LNK

$\$$ PURGE

$\$$ RUN 'P2'

RUN THIS COMMAND FILE ON LINE AS:

@FINDIF MDLID MDLIDBNY

OR ON THE BATCH QUEUE AS:

SUBMI T / QUEUE=VAXPEGASO \$BATCH -

FINDIF $/$ PARAM $=($ MDLID, MDLIDBNY $)$, CPUTIME $=0$

FINDIF USERS SHOULD COPY ALI THE FILES FROM

[AKAL.RALPH.FINDIE] TO A SUB-DIRECTORY IN THEIR

AREA AND THEN EDIT THE 'SET DEF' IN THIS FILE

TO REFER TO THEIR OWN WORK AREA.

SET VERIEY

Define directories

SET DEF [AKAL.RALPH]

PURGE

ASSIGN 'P1'.PAR FOR055 !input parameter file

ASSIGN 'P1'.BNY FOR054 !output data file

QSCNTPREP . LNK

PURGE

RUN SCNTPREP 
$\$ !$

\$ QSCNTDIF.LNK

$\$$ PURGE

$\$$ RUN SCNTDIF

\$ SH DEF

$\$$ DIR

$\$$ EXIT

$\$ !$

\$! End of command file

$\$ !$

3e) Summary of Subroutines and 'INCLUDE' Files

A summary of SCNTDIF subroutines and the 'INCLUDE' files, which contain 'COMMON' blocks, are listed below.

DATIM

SCNTS9

SCNTSUB7

SFSETUP

SLOGOUT

SOPNCOM

SRDMPAR

ZDIVCRL,ZSNPOUT

ZTSOUT

TIMIT

SCOMFD8.FOR

SMODPAR.FOR

SIOUNIT.FOR

SCBLCK.FOR
- obtains the date and time of the run which is written in the log files (this capability is disabled for the FPS264 but can be easily implemented again on the VAX 9000);

- applies the finite difference template to the grid;

- defines constants used in the template calculations;

- opens the *.BNY file;

- outputs model parameters in a standard format for all log files;

- opens the 'COMMON' block files;

- reads the *.PAR file;

- outputs the snapshot files;

- outputs the time series files;

- calls machine routines to obtain run time paramaters during execution (this capability is disabled for the FPS264 but can be easily implemented again on the VAX 9000);

- 'INCLUDE' file which contains 'COMMON' blocks of working arrays with dimensions which are model dependent;

- 'INCLUDE' file which contains 'COMMON' blocks of the model parameters;

- 'INCLUDE' file which contains 'COMMON' blocks of all logical unit names for SCNTDIF;

- 'INCLUDE' file which contains 'COMMON' blocks of the constants used in the wave equation template. 


\section{Running SCNTDIF}

The first step in running SCNTDIF is to design the model on a sheet of paper (Figure 9). First decide what peak frequency (in $\mathrm{Hz}$ ) you would like to consider ( see the note above on scaling). Aim for models that are at most 40 water wavelengths deep and 70 water wavelengths long. These will take about 20 hours on the FPS264. (This assumes 10 gridpoints per water wavelength. If finer spacing is used to model shear and Stoneley waves in soft sediments the model dimensions should change accordingly.). The grid increment, DELX, should be at most one tenth of a wavelength. Remember that for shear and interface waves in sediments the wavelengths can be quite small. Now decide the range and depth values (in $\mathrm{km}$ ) that you would like and compute the grid dimensions. Remember that the absorbing boundary region takes 90 gridpoints on the right side and on the bottom.

For stability DELT must be less than DELR/[(root 2)*vpmax)] where vpmax is the largest velocity on the grid. It is nice to choose a DELT which divides evenly into one second (eg. .01 , $.0125,01666$, etc). Now determine to what time duration you would like results and compute the number of time steps. You will now have the basic model size defined.

The next step is to determine the dimensions for the 'transition zone' and to decide on velocity and density values for the upper and lower homogeneous regions. Make decisions on receiver locations, the time series sampling rate and the frequency and type of snapshots.

The next step is to conceive the structure for the transition zone region and to modify or write the *BNY code to generate the matrices of elastic parameters and density.

Go through the list of input parameters and confirm that each one is specifying what you want. You are now ready to go the computer.

Set up a sub-directory for each model. Choose an example that is close to what you want to do and copy the example *.PAR and *.BCH files to the new directory. (An example of a *.PAR file was given in Figure 3 and an example of a *.BCH file is given in Figure 10.) Edit the *.PAR file to contain the new model name and the new parameters. Edit the *.BCH file to use the new model name $(M D L I D)$ and confirm that the correct *BNY file is being used.

If you are modifying an existing *BNY file or writing a new one, make the changes to the file in the PR19_DISK:[STEPHEN.BENCH.FPS.BNY] directory (or in your own work area if running on the $\bar{V} A X 9000$ ). Edit the command file in this directory to change the program name (eg. change every occurence of CAI01BNY with the new name). Then run the command file in PR19_DISK:[STEPHEN.BENCH.FPS.BNY] to insure that the code compiles.

Now go back to the model directory and submit the .BCH file to the FPS queve (or FINDIF.COM to the batch queue on the VAX9000, VAXPEGASO\$BATCH. 


\section{MODEL $\underline{\mathrm{CAlO4}}$}

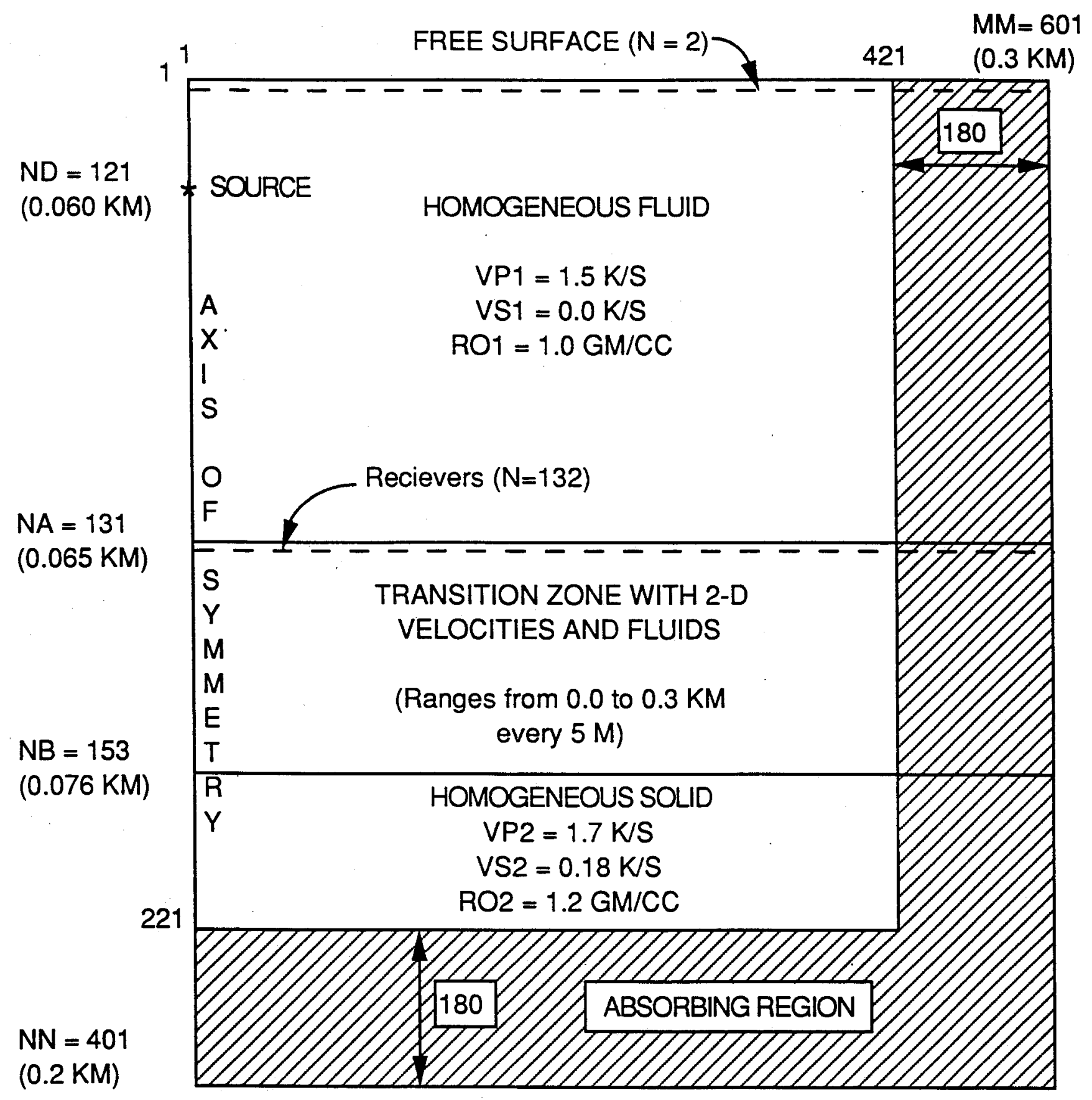

DELR: $0.0005 \mathrm{KM}$

SOURCE PEAK FREQUENCY: $100 \mathrm{HZ}$ (PLSWID = 6.5746)

WATER WAVELENGTHS (1.5/FPEAK): 15M

GRIDPOINTS/WAVELENGTH: 30 for P-WAVES IN WATER

STABILITY: $\{$ DELT $=0.0001\}<\{$ DELR/(SQRT(2)*VPMAX $)=0.00021\}$

DURATION $=\{K K=20,000\}^{*} \mathrm{DELT}=2.0 \mathrm{SEC}$

RECEIVER LOCATIONS: $N=132$ : $M=1,601,10$ 
Figure 10. Example of the CAI04.BCH file.

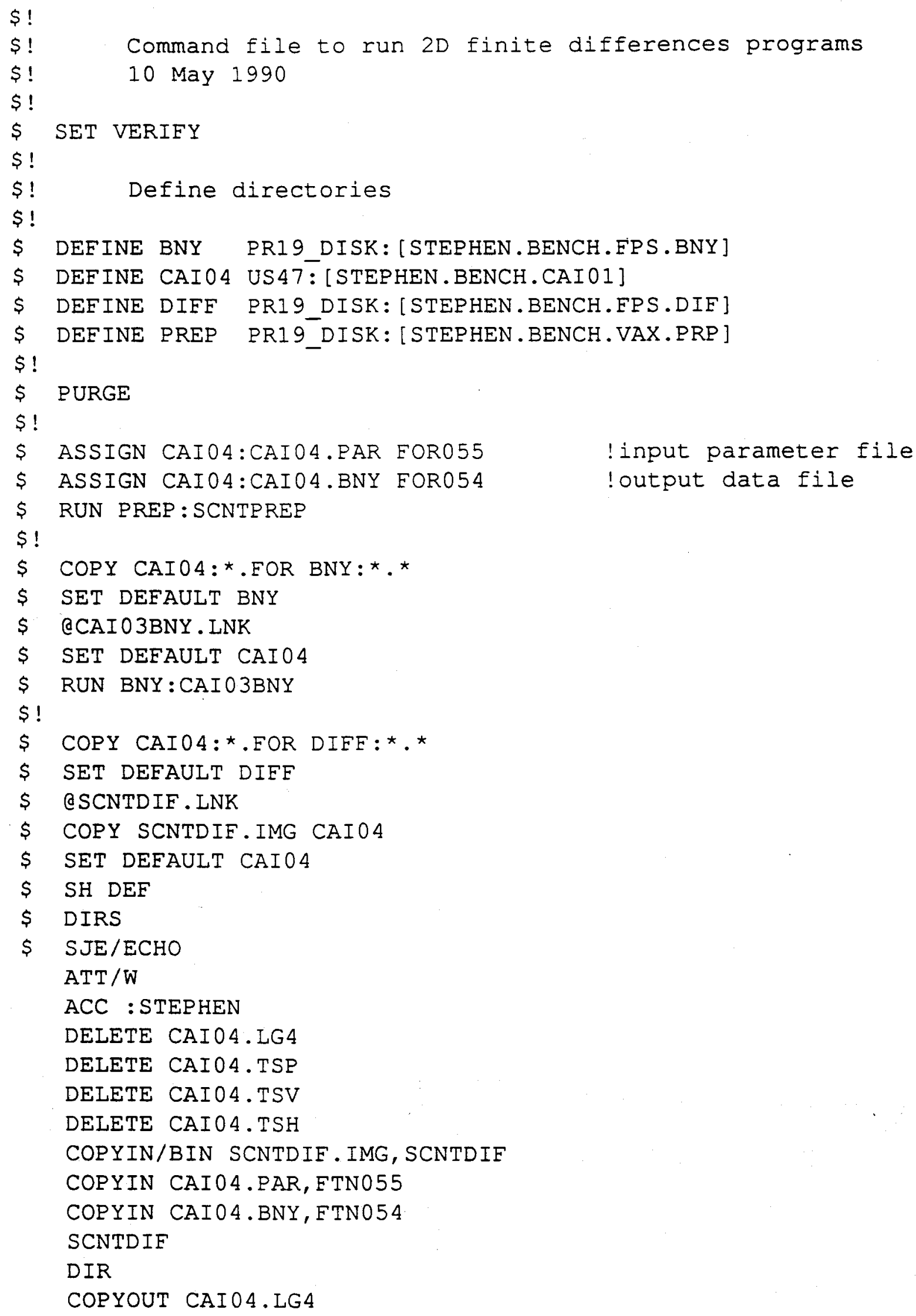

$\$ !$

$\$$ SET VERIFY

$\$ !$

$\$ !$

$\$ !$

$\$$ DEFINE BNY PRI9 DISK: [STEPHEN.BENCH.FPS.BNY]

$\$$ DEFINE CAIO4 US47:[STEPHEN.BENCH.CAI01]

$\$$ DEFINE DIFF PRI9_DISK:[STEPHEN.BENCH.EPS.DIF]

$\$$ DEFINE PREP PRI9_DISK:[STEPHEN.BENCH.VAX.PRP]

$\$ !$

\$ PURGE

$\$ !$

$\$$ ASSIGN CAI04:CAI04.PAR FOR055

! input parameter file

$\$$ ASSIGN CAIO4:CAI04.BNY FORO54

loutput data file

\$ RUN PREP:SCNTPREP

$\$ !$

$\$$ COPY CAIO4:*.EOR BNY:*.*

$\$$ SET DEFAULT BNY

$\$$ CCAI03BNY.LNK

$\$$ SET DEFAULT CAIO4

\$ RUN BNY:CAIO3BNY

$\$ !$

$\$$ COPY CAI04:*.EOR DIFE:* .*

$\$$ SET DEFAULT DIEF

$\$$ QSCNTDIF.LNK

\$ COPY SCNTDIF.IMG CAIO4

$\$$ SET DEFAULT CAIO4

$\$$ SH DEF

$\$$ DIRS

\$ SJE/ECHO

$\mathrm{ATT} / \mathrm{W}$

ACC : STEPHEN

DELETE CAI04.LG4

DELETE CAI04.TSP

DELETE CAI04.TSV

DELETE CAIO4.TSH

COPYIN/BIN SCNTDIE.IMG, SCNTDIF

COPYIN CAI04.PAR, FTN055

COPYIN CAI04.BNY, FTN054

SCNTDIF

DIR

COPYOUT CAI04.LG4 


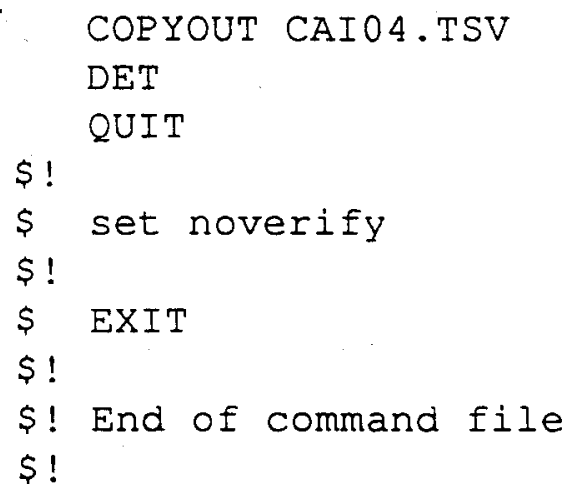

If the job has finished properly, snapshot and time series files should have appeared in your model directory. The MDLID.LG4 file should contain run time information and may have error messages if the job stopped early. Andrea Caiti has experience plotting the time series files using a format similar to SAFARI. One set of snapshot files were plotted for Tuncay Akal (AKA02). These should be used in conjunction with the time series to get insight into the multi-pathing and scattering effects.

\section{Examples}

Preliminary models, addressing particular research issues at the Centre, were run for a number of investigators. The objective was to set up basic models that could be subsequently modified by individual investigators to meet their research needs. Most of these models were run on the VAX8600/FPS264 because the VAX9000 arrived only a month before the contract period finished. We discuss these models below. For convenience they are organized under the name of the investigator most closely related each study.

\section{5a) Andrea Caiti}

The first example considered was run for Andrea Caiti and represents a near bottom point source at $100 \mathrm{~Hz}$ in shallow water over a sedimentary bottom consisting of two layers and a halfspace (Figure C-1). The model name is CAI04. CAI04.PAR is given in Figure 3 and CAI04.BCH is given in Figure 10. The values in the transition zone are defined using CAI03BNY.FOR and this is given in Figure C-2. Time series for the vertical particle velocity, horizontal particle velocity, and pressure for a horizontal line of receivers on the seafloor are shown in Figure C-3.

The second example, CAI05, is the same as CAI04 but the source frequency has been changed to $10 \mathrm{~Hz}$. The time series results are shown in Figure $\mathrm{C}-4$.

For comparison, Figure C-5 shows examples of the field data that Andrea is studying. The major phases (direct water wave, water wave multiples, Stoneley wave and higher order Stoneley waves) are present in both the field data and synthetics. Note that the water waves are not supported by the shallow wave guide in the low frequency case. Also note that since the code is solving the line source problem body wave amplitudes in the synthetics decay as (1./SQRT(R)) rather than (1/R) for the point source used in the field. (A two dimensional code in cylindrical co-ordinates, which does not have this problem, is available but is not yet implemented at SACLANTCEN.)

CAI01 was a preliminary test model for a $100 \mathrm{~Hz}$ source in shallow water $(65 \mathrm{~m})$ over a homogeneous sediment $\left(V_{p}=1.7 \mathrm{k} / \mathrm{s}, V_{s}=0.45 \mathrm{k} / \mathrm{s}\right.$ and density $\left.=1.42 \mathrm{gm} / \mathrm{cc}\right)$ out to ranges of $300 \mathrm{~m}$ for a duration of $0.2 \mathrm{sec}$. CAI02 was the same as CAI01 but with a shear velocity in the sediment of $0.18 \mathrm{k} / \mathrm{s}$, which was more representative of sediments in Andrea's test area. CAI03 was the same as 
CAI02 but had a layered bottom with parameters corresponding to Andrea's test area. CAI04 was the same as CAI03 but was run to $2.0 \mathrm{sec}$ duration to show the Stoneley wave better. CAI05 was the same as CAI04 but for a $10 \mathrm{~Hz}$ source. CAI09 was the same as CAI02 (soft, homogeneous bottom) but for a $10 \mathrm{~Hz}$ source.

CAI06 was a homogeneous water model with the same source/receiver geometry as the previous runs. CAI06 was run to determine the far-field source strength in homogeneous water for the $100 \mathrm{~Hz}$ case and to check the amplitude decay with range. CAI07 was a similar normalization test for a broadband pulse from $10-100 \mathrm{~Hz}$. This source could be used to combine the low and high frequency effects (CAI04 and CAI05) in the same model. This study was not finished.

CAI10 and CAI11 were hard, homogeneous bottom examples (shear velocity in the bottom higher than water velocity, $V_{p}=4.0 \mathrm{k} / \mathrm{s}, \mathrm{V}_{\mathrm{s}}=2.3 \mathrm{k} / \mathrm{s}$ and density $=2.3 \mathrm{gm} / \mathrm{cc}$ ) with the same source/ receiver geometry as CAI01 for $100 \mathrm{~Hz}$ and $10 \mathrm{~Hz}$ sources respectively. They demonstrate the change in behaviour of the Stoneley and pseudo-Rayleigh waves for hard bottoms.

CA108 was a hard, homogeneous bottom test for a $10 \mathrm{~Hz}$ source in a $100 \mathrm{~m}$ channel for comparison with some results from WHOI. CAI12 was the same as CAI08 but the top free surface was replaced with a plane of symmetry. CAI08 and CAI12 had receivers on the top surface. CAI13 was the same as CAI12 for receivers on the seafloor.

On-going work in this 'Caiti' area involved running a standard flat model with both SAFARI and SCNTDIF for comparison. Also the flat model could be further refined to agree better with the field data. Andrea had computed dispersion plots (group velocity versus frequency) to help in this area. Ultimately the study would include range dependent structure, such as bathymetry or volume heterogeneities in the sediment.

\section{5b) Tuncay Akal}

The work with Tuncay Akal was similar to the work with Andrea Caiti. In Tuncay's case the frequency was $100 \mathrm{~Hz}$ but the water depth was only $18 \mathrm{~m}$ and there were eight layers in the subbottom. AKA01 had the source midway in the water column and AKA02 had the source $0.5 \mathrm{~m}$ above the seafloor. AKA02 was used as a test model for plotting the divergence and curl snapshots. The snapshot plots look fine and it is highly recommended that these be plotted and used for interpretation.

\section{5c) Jens Hovem}

One model was run for Jens Hovem (HOV01) to study tunnelling effects, interface waves and shear waves in thin, soft sediment layers over-lying hard basalt. This model is similar to the Caiti and Akal models in that it uses a pulsed point source in the water over a stratified bottom and a horizontal line of recievers. It has a thick water layer to avoid interference of the free surface reflection with the bottom interacting path.

5d) Dale Ellis

One model was also run for Dale Ellis (ELL01) to study the effects of backscattering from rough seafloors to a vertical array. This model set the stage for summer work by Nicolas Kampanis which is outlined in the report, "Bottom backscattering calculations using a time-domain finitedifference code for the elastic wave equation - by Kampanis, N.A., Ellis, D.D. and Stephen, R.A."

5e) Dan Lott

The work for Dan Lott focussed on comparing the response of the seafloor to omni-directional point sources (explosions) and vector point forces (weight drops). The code was modified to 
handle the point force as an option. We used the same bottom model as in AKA01. LOT01 is a point force applied in the sediment. LOT02 is an omni-directional point source applied in the sediment. LOT03 is a point force applied on the surface of the sediment. In all cases the time dependence is a $100 \mathrm{~Hz}$ Gaussian pulse.

5f) John Preston reverberation.

Models were set up for John Preston in his work area on the VAX9000 to study basin

\section{Computation Time}

Table 1 summarizes some typical run times for SCNTDIF on the FPS264. Computation time is dependent on the number of range points (MM), the number of depth points $(\mathrm{NN})$, the number of time points $(\mathrm{KK})$, and the width of the transition zone region (NB-NA+1). Roughly speaking the time in microminutes for a job is $0.2 *(\mathrm{NN}+\mathrm{NB}-\mathrm{NA}+1) * \mathrm{MM} * \mathrm{KK}$.

Table 1: Typical Run Times for the SCNTDIF code on the VAX8600/FPS264 at SACLANTCEN (These are elapsed times and will vary for a particular job depending on the load on the system.)

\begin{tabular}{lclrlllrr} 
Model & & & & & & ELAPSED & ELAPSED & FORMULA \\
Name & MM & NN & \multicolumn{1}{l}{ KK } & NB-NA+1 & TIME & TIME & TIME \\
AKA01 & 601 & 401 & 20,001 & 45 & $16 \mathrm{~h} 52 \mathrm{~m}$ & $1,012 \mathrm{~m}$ & $1,072 \mathrm{~m}$ \\
CAI01 & 601 & 401 & 2,001 & 103 & $03 \mathrm{~h} 09 \mathrm{~m}$ & $189 \mathrm{~m}$ & $121 \mathrm{~m}$ \\
CAI04 & 601 & 401 & 20,001 & 23 & $20 \mathrm{~h} 31 \mathrm{~m}$ & $1,231 \mathrm{~m}$ & $1,019 \mathrm{~m}$ \\
ELL01 & 601 & 501 & 2,501 & 31 & $01 \mathrm{~h} 50 \mathrm{~m}$ & $110 \mathrm{~m}$ & $160 \mathrm{~m}$ \\
CAI08 & 601 & 401 & 2,001 & 2 & $01 \mathrm{~h} 31 \mathrm{~m}$ & $90 \mathrm{~m}$ & $97 \mathrm{~m}$ \\
HOV01 & 1001 & 801 & 12,001 & 39 & $204 \mathrm{~h} 16 \mathrm{~m}$ & $3,136 \mathrm{~m} *$ & $2,018 \mathrm{~m}$ \\
(* - this job was running & on the FPS260 with many other jobs.)
\end{tabular}

Run times on the VAX9000, in scalar mode, are about a factor of three less than on the FPS264. The code as currently configured runs in about the same time in scalar and vector modes on the VAX9000.

\section{Recommended Modifications}

There are a number of modifications that would make SCNTDIF more useful for some projects at SACLANTCEN:

a) Adding the capability to treat a cylindrical coordinate geometry;

b) Adding intrinsic attenuation;

c) Adding a broader bandwidth source;

d) Putting a point force in the VAX9000 code;

e) Putting an absorbing boundary on the left hand side of the Cartesian coordinate system code. 
Hunt,M.M. and Stephen,R.A.,1986,WHOI-4-86.

Levander,A.R.,1985,Bull.Seism.Soc.Am.,75,1847-1852.

Nicoletis,L.M.,1981,PhD Thesis, U of Paris VI.

Stephen,R.A.,1983,Geophys.J.R.astr.Soc.,72,39-58.

Stephen,R.A., 1984,Geophys.J.R.astr.Soc.,79,184-198.

Stephen,R.A.,1988a,J.Geophys.Res.,93,6571-6584.

Stephen,R.A., 1988b,Rev.Geophys.,26,445-458.

Stephen,R.A., 1990,J.acoust.Soc.Am.,87,1527-1534.

Stephen,R.A. et al,1985,Geophysics,50,1588-1609.

Virieux,J.,1986,Geophysics,51,889-901. 

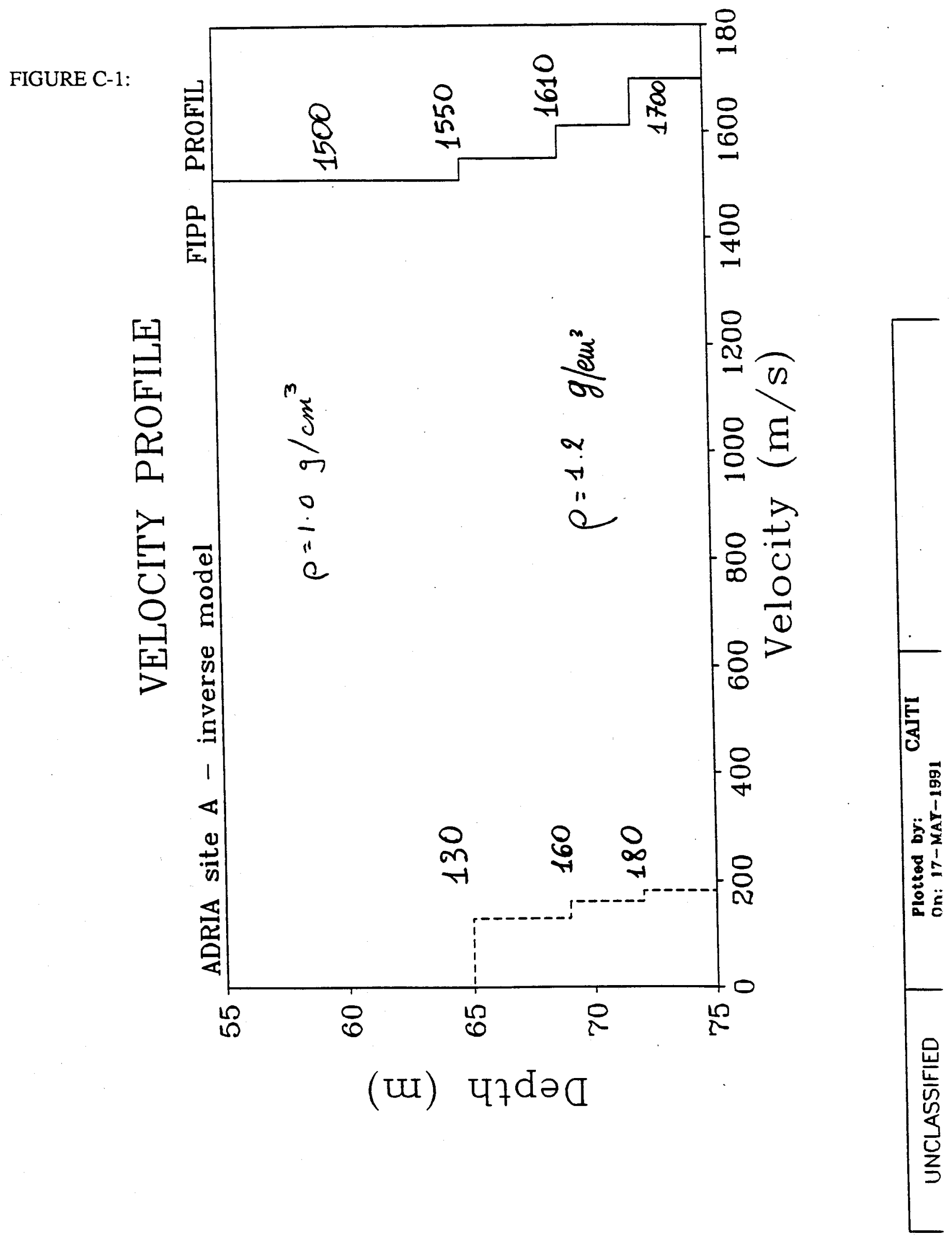

page 21 
FIGURE C-2: CAI03BNY.FOR

C

C

C

C

C

C

C

C

C

C

C

C

C

C

C

C

C

C

C

C

C

C

C

C

C

C

C

C

C

C

C.

C

C

.

PROGRAM CAI03BNY.FOR

FDBNY JULY 9, 1983

PROGRAM FDBNY

COPYRIGHT WOODS HOLE OCEANOGRAPHIC INSTITUTION 1988

ALL RIGHTS RESERVED

ORIGINAL VERSION 1 SEPT 1980

BY RALPH STEPHEN

SETS UP TRANSITION ZONE VELOCITY STRUCTURE FOR FINDIF8

RETURNS MATRICES OF P- AND S- VELOCITY SQUARED AND DENSITY FOR THE MODEL GIVEN.

THE DIMENSIONS ARE MM AND NBNDY ( NBNDY=NB-NA+3).

THE TOP AND BOTTOM ROWS OF VP32 AND VS32 MUST BE VP1**2, VS1**2 AND VP2**2 AND VS2**2 RESPECTIVELY.

COSMETIC SURGERY BY MARY HUNT, JUNE 1983

INCLUDE 'SCOMFD8.FOR'

INCLUDE 'SMODPAR.FOR'

INCLUDE 'SIOUNIT.FOR'

CHARACTER *5 FILEID

CHARACTER *9 VERDAT

CHARACTER * 12 FILNAM

DATA VERDAT /'9-JUL-83’/

$$
\begin{aligned}
& \text { LUINP }=55 \\
& \text { LUBNY }=54 \\
& \text { LULOG }=66 \\
& \text { LUTRM }=6
\end{aligned}
$$

SET UP I/O UNIT NUMBERS

READ INPUT PARAMETERS, START LOG FILE.

CALL RDMPAR ( LUINP, FILEID, 'FDBNY ‘) 
CALL LOGOUT ( LULOG, FILEID, 'FDBNY ', VERDAT )

C

$\mathrm{C}$

C

C

C

C

C

$\mathrm{C}$
$\mathrm{C}$
$\mathrm{C}$

$\mathrm{C}$
$\mathrm{C}$
$\mathrm{C}$

$\mathrm{C}$
$\mathrm{C}$
$\mathrm{C}$

$$
\begin{array}{cc}
\text { FILNAM }=\text { FILEID } / / \text { ' } . B N Y \\
\text { OPEN }(\text { UNIT }=\text { LUBNY, } \\
+\quad \text { FILE }=\text { FILNAM, } \\
+\quad \text { STATUS }=\text { 'NEW' })
\end{array}
$$

WRITE (LUBNY,*) IEXPL, IDENS, MM, NA, NB

WRITE (LUBNY,*) VP1, VS1, RO1, VP2, VS2, RO2

\section{START COMPUTATIONS}

$$
\mathrm{NBNDY}=\mathrm{NB}-\mathrm{NA}+3
$$

IF ( ITRAN .EQ. 1 .OR. ITRAN .EQ. 2 ) NBNDY = NBNDY -1

NBM1 $=$ NBNDY -1

NBM2 = NBM1-1

$\mathrm{XNBM} 1=\mathrm{NBM} 1$

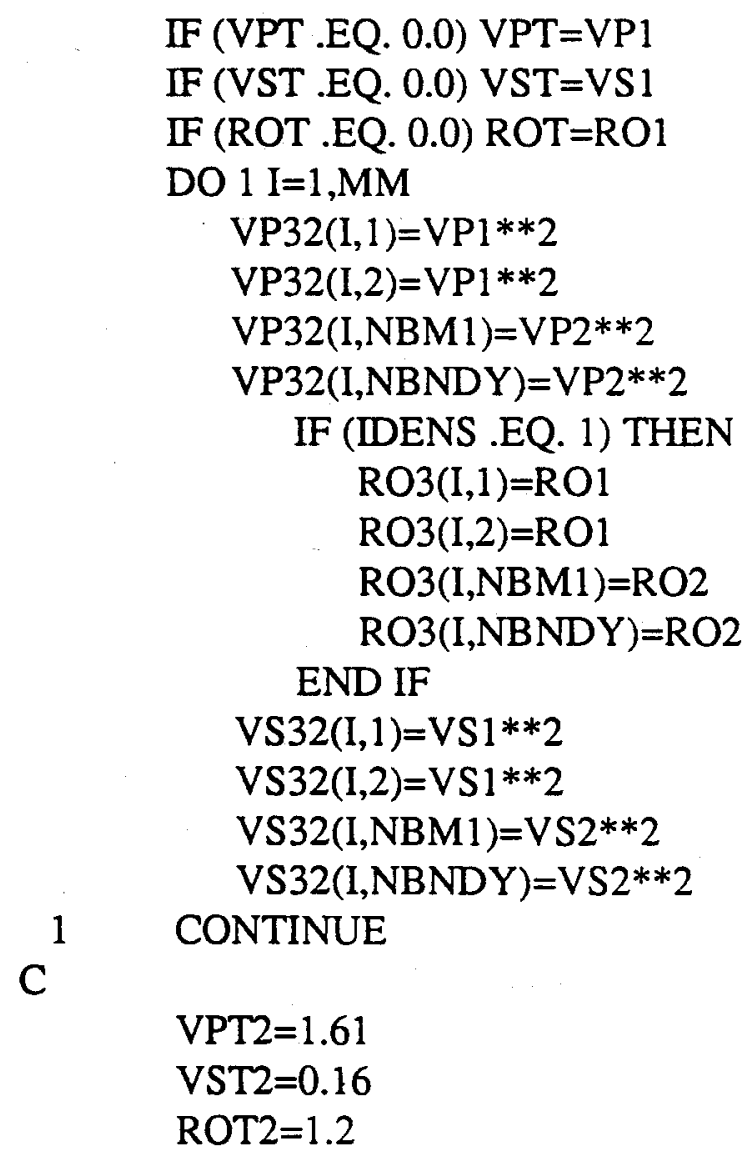

VPT $2=1.61$

VST2 $=0.16$

ROT2 $=1.2$ 
C

$$
\begin{aligned}
& \text { VPT } 1=1.55 \\
& \text { VST } 1=0.13 \\
& \text { ROT } 1=1.2
\end{aligned}
$$

C

$$
\begin{aligned}
& \text { JST1 }=3 \\
& \text { JEN1 }=10 \\
& \text { JST2 }=11 \\
& \text { JEN2 }=16
\end{aligned}
$$

C

$$
\begin{gathered}
\text { DO } 801 \mathrm{I}=1, \mathrm{MM} \\
\text { DO } 805 \mathrm{~J}=\mathrm{JST} 1, \mathrm{JEN} 1 \\
\text { VP32(I,J)=VPT } 1 * * 2 \\
\text { VS32(I,J)=VST } 1 * * 2 \\
\text { RO3(I,J)=ROT1 }
\end{gathered}
$$

805 CONTINUE

$$
\text { DO } 806 \mathrm{~J}=\mathrm{JST} 2 \text {,JEN2 }
$$

$$
\begin{aligned}
& \mathrm{VP} 32(\mathrm{I}, \mathrm{J})=\mathrm{VPT} 2 * * 2 \\
& \mathrm{VS} 32(\mathrm{I}, \mathrm{J})=\mathrm{VST} 2 * * 2
\end{aligned}
$$

$$
\mathrm{RO} 3(\mathrm{I}, \mathrm{J})=\mathrm{ROT} 2
$$

806

$$
\text { CONTINUE }
$$

$$
\text { DO } 808 \mathrm{~J}=\mathrm{JEN} 2+1, \mathrm{NBM} 2
$$

$$
\begin{aligned}
& \text { VP32(I,J)=VP2 } * * 2 \\
& \text { VS32(I,J)=VS2 } * * 2 \\
& \text { RO3(I,J)=RO2 }
\end{aligned}
$$

808 CONTINUE

801 CONTINUE

C

C OUTPUT TO LOG FILE AND BOUNDARY FILE.

C

$$
\begin{aligned}
& \mathrm{ID}=\mathrm{MM} / 10+1 \\
& \text { WRITE (LULOG,2000) MM, D, NBNDY }
\end{aligned}
$$

2000 FORMAT ( $1 \mathrm{X}$, 'VP**2 IN TRANSITION ZONE,

$$
\left.+\quad(\mathrm{I}, \mathrm{J}), \mathrm{I}=1,{ }^{\prime}, \mathrm{I} 4,{ }^{\prime},{ }^{\prime}, \mathrm{I} 3,{ }^{\prime} \mathrm{J}=1,{ }^{\prime}, \mathrm{I} 4\right)
$$

WRITE (LULOG,2010) ( (VP32(I,J),I=1,MM,ID),J=1,NBNDY)

2010 FORMAT ( 1X, 10F7.2)

C

WRITE (LUBNY,*) VP32

WRITE (LUBNY,*) VS32

IF (IDENS .EQ. 1) WRITE (LUBNY,*) RO3

C

CLOSE (UNIT $=$ LUBNY)

CLOSE (UNIT $=$ LULOG)

C

STOP

END 
FIGURE C-3A:

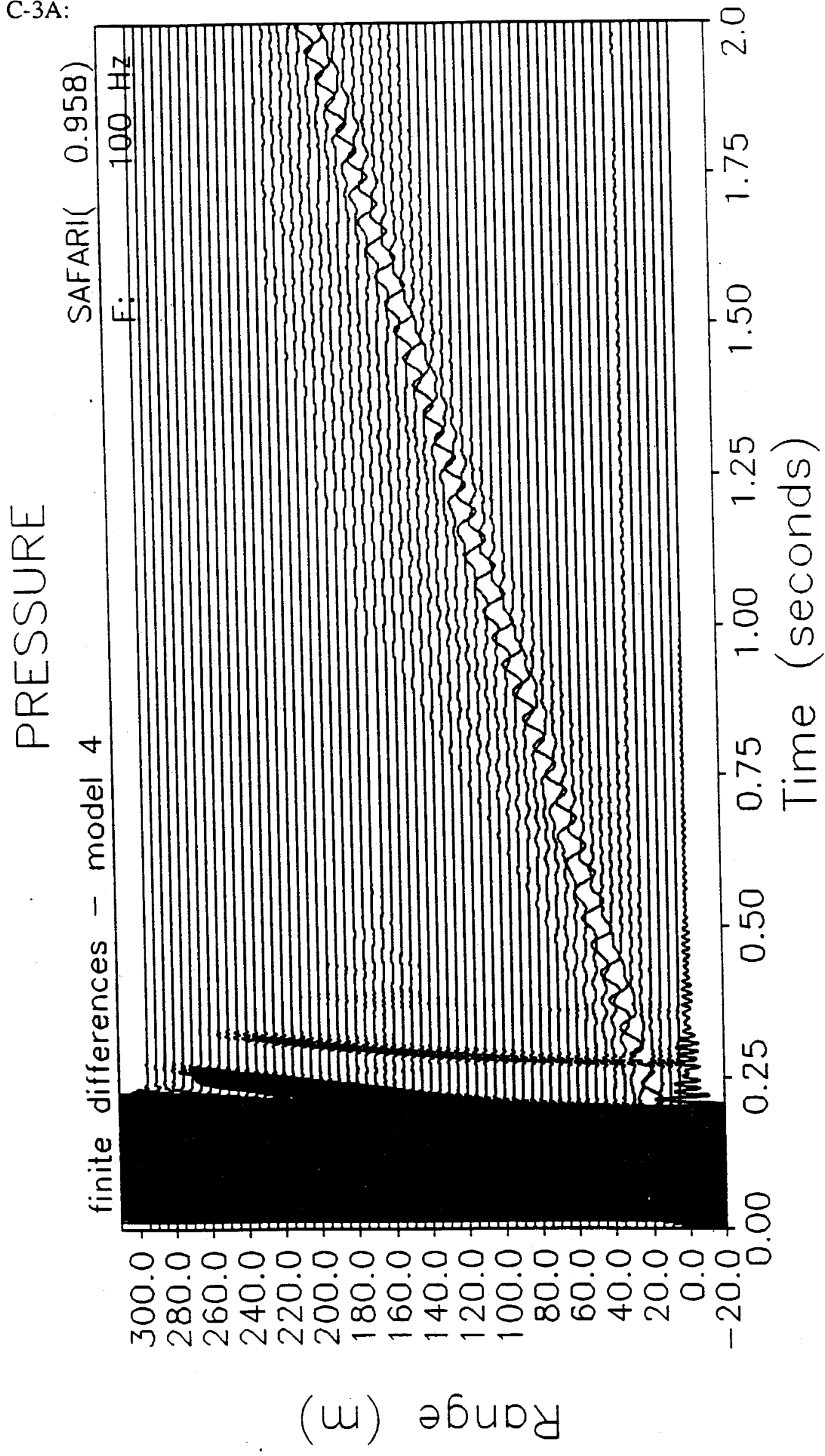


FIGURE C-3B:
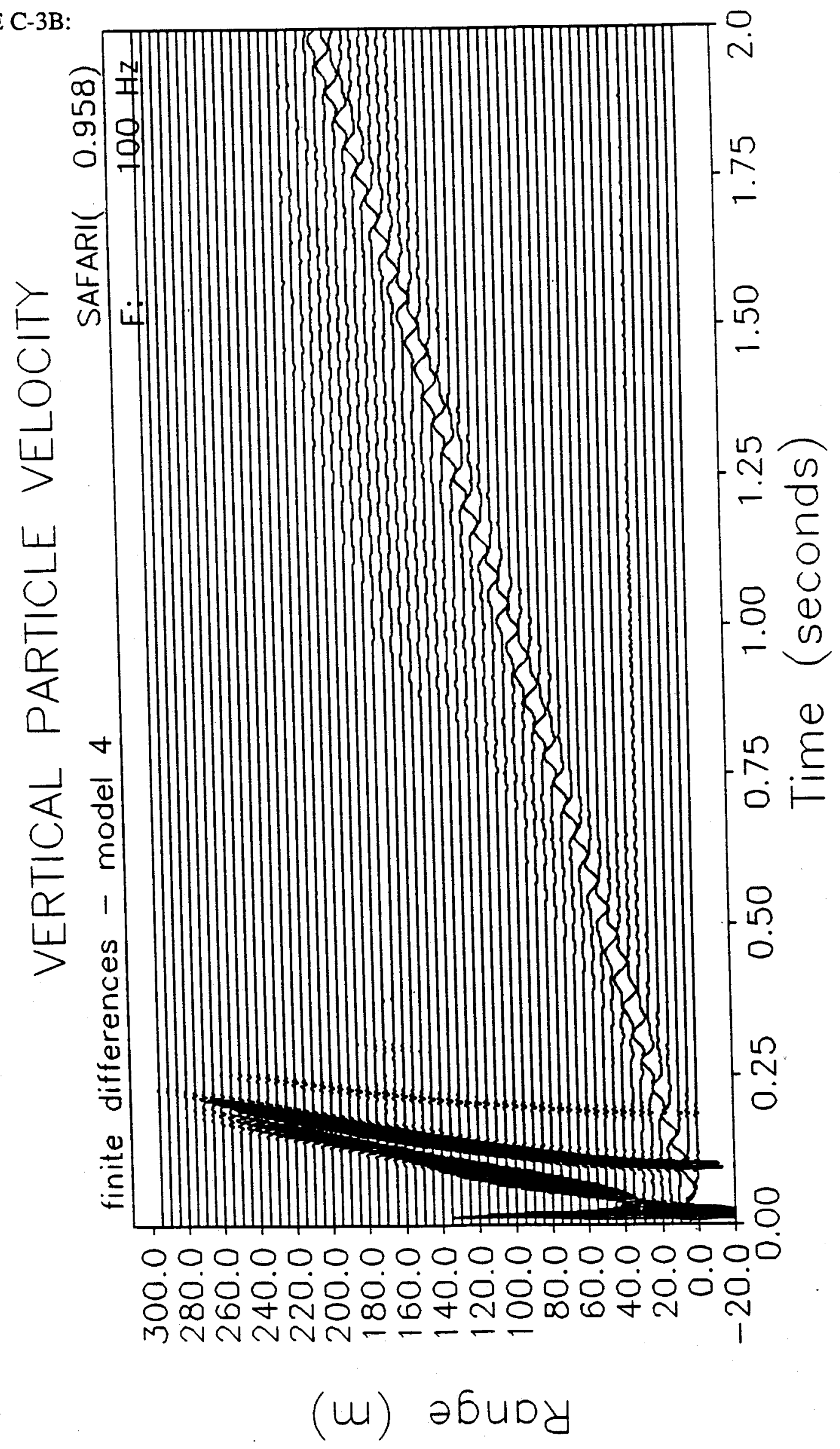
FIGURE C-3C:

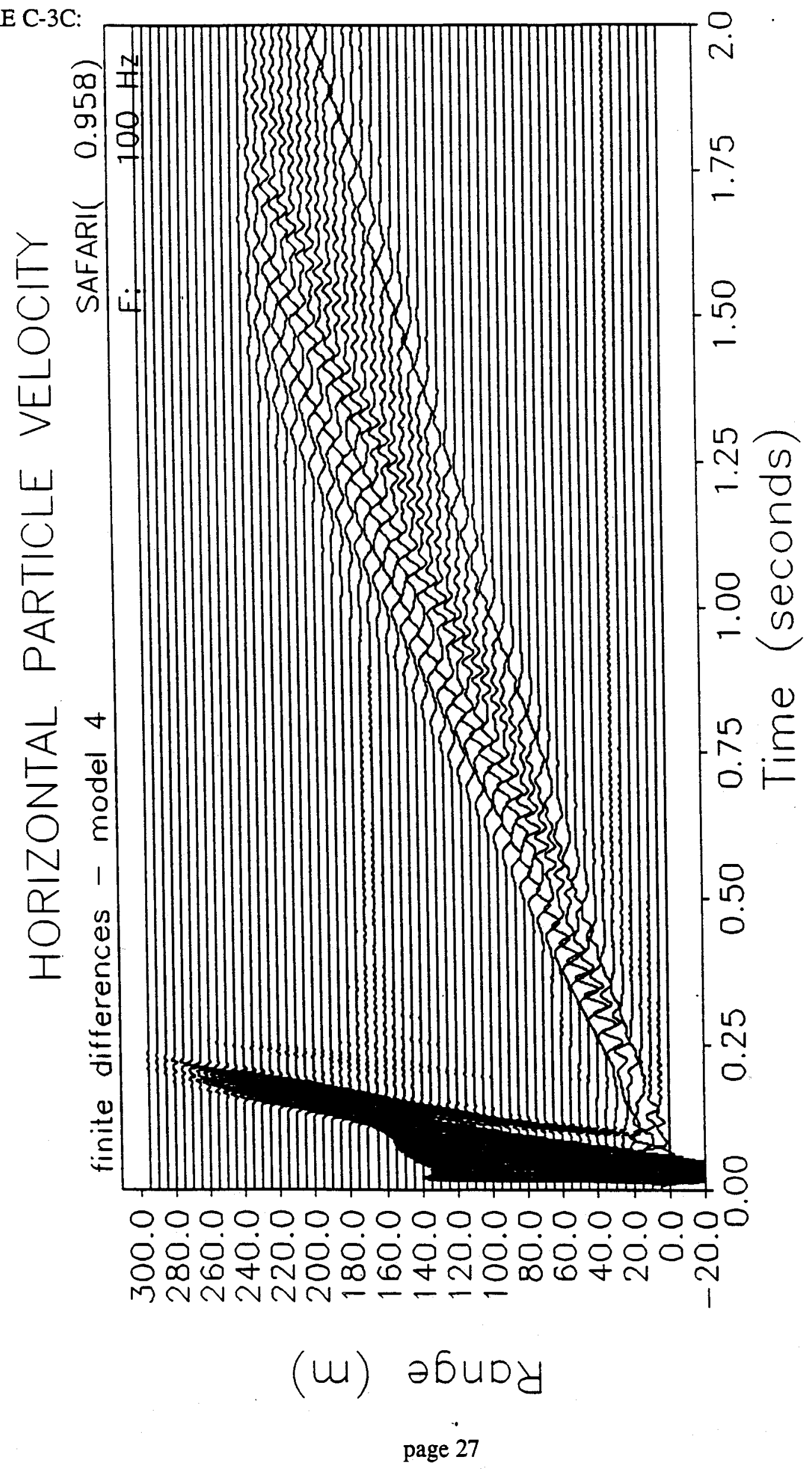


FIGURE C-4A:

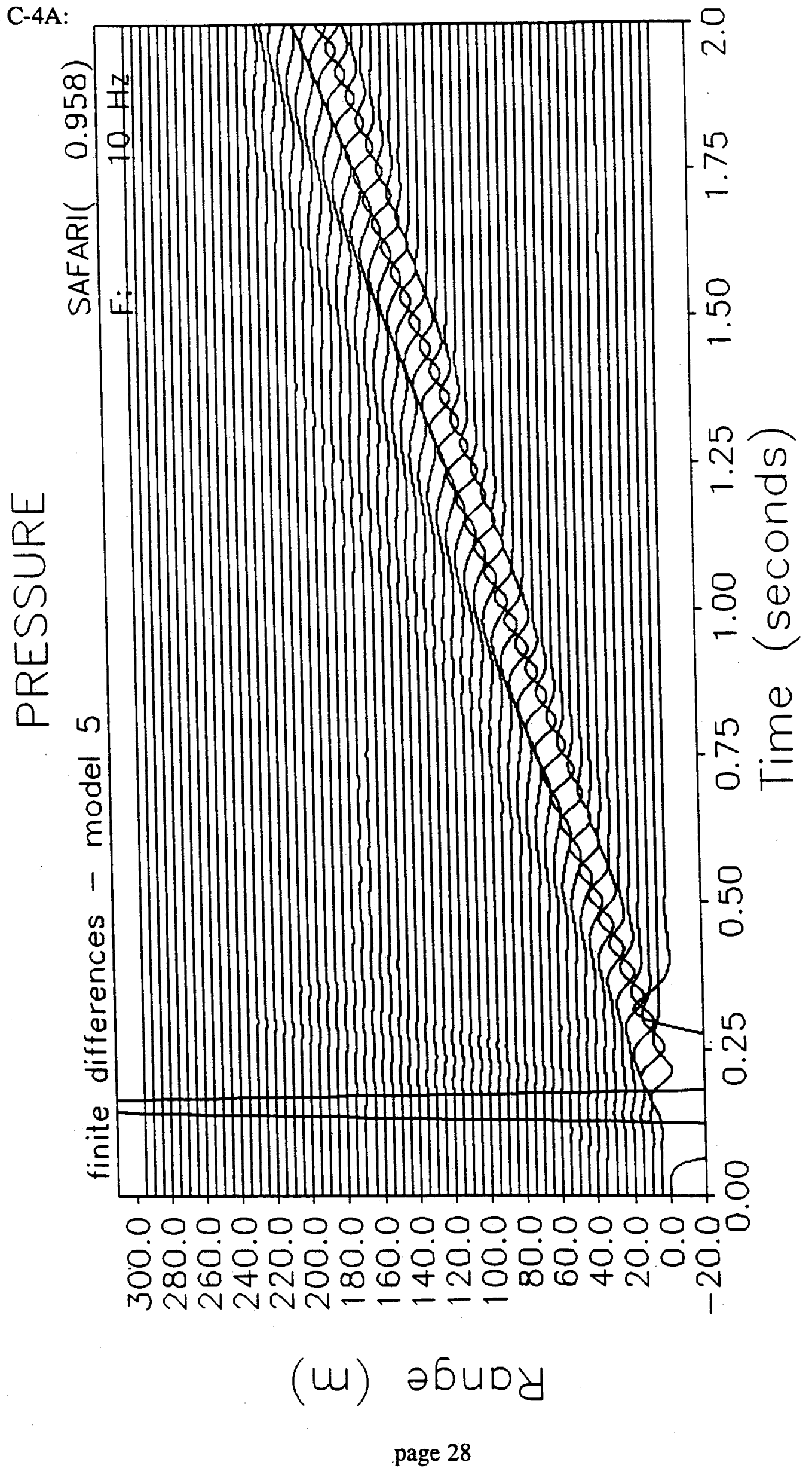


FIGURE C-4B:

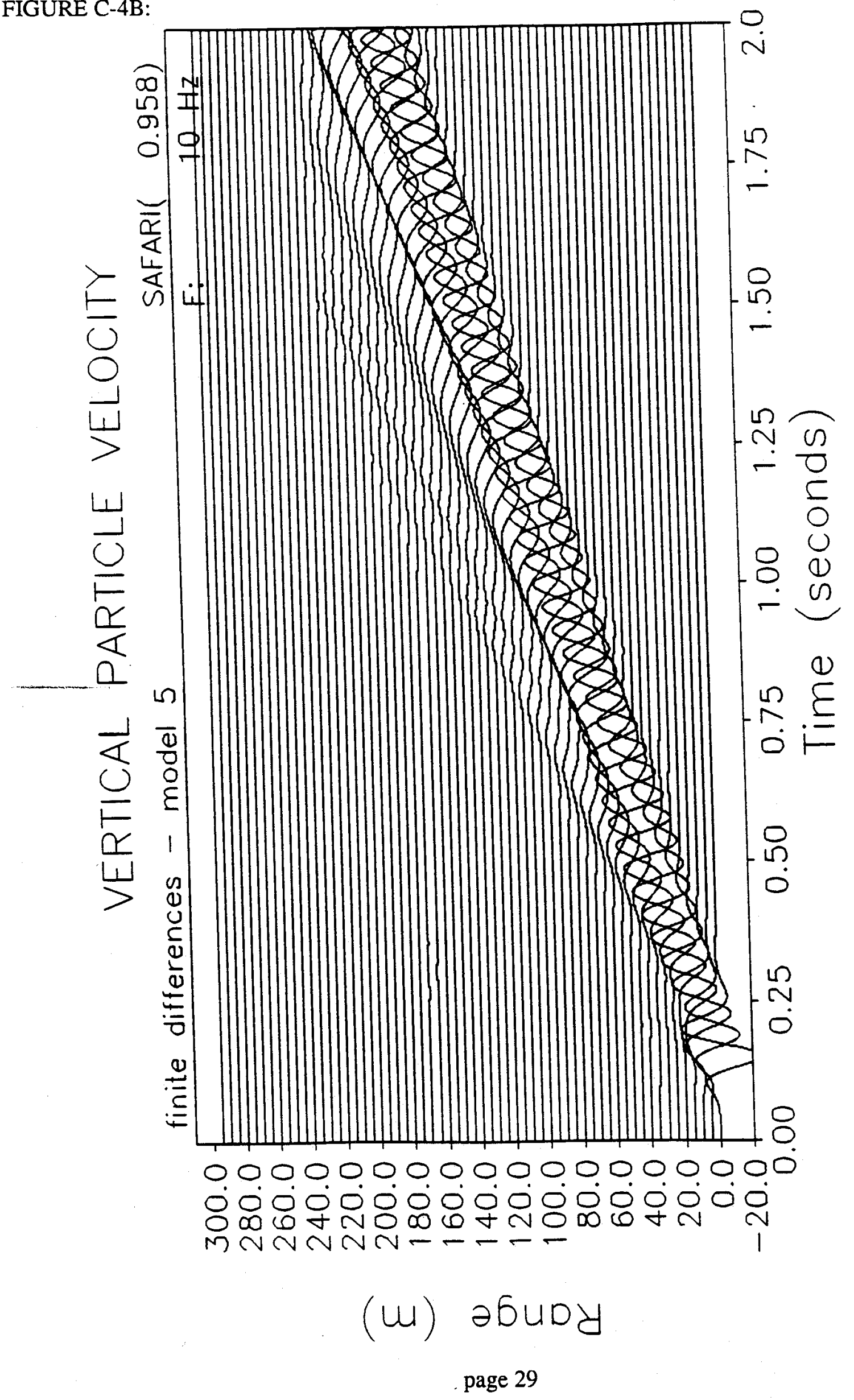


FIGURE C-4C:

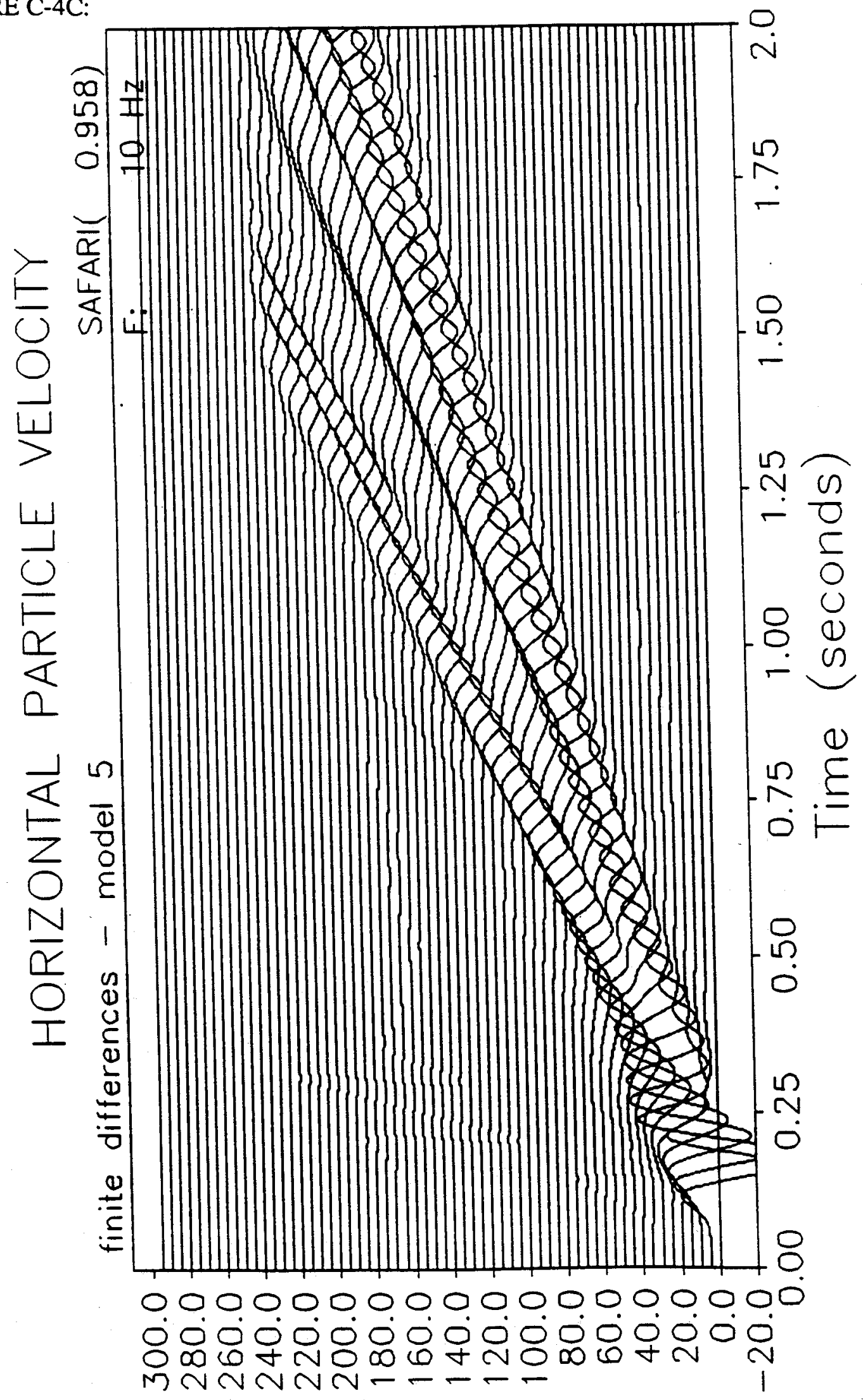

$$
\begin{gathered}
\text { (u) } 2 \text { budy } \\
\text { page } 30
\end{gathered}
$$


FIGURE C-5A:

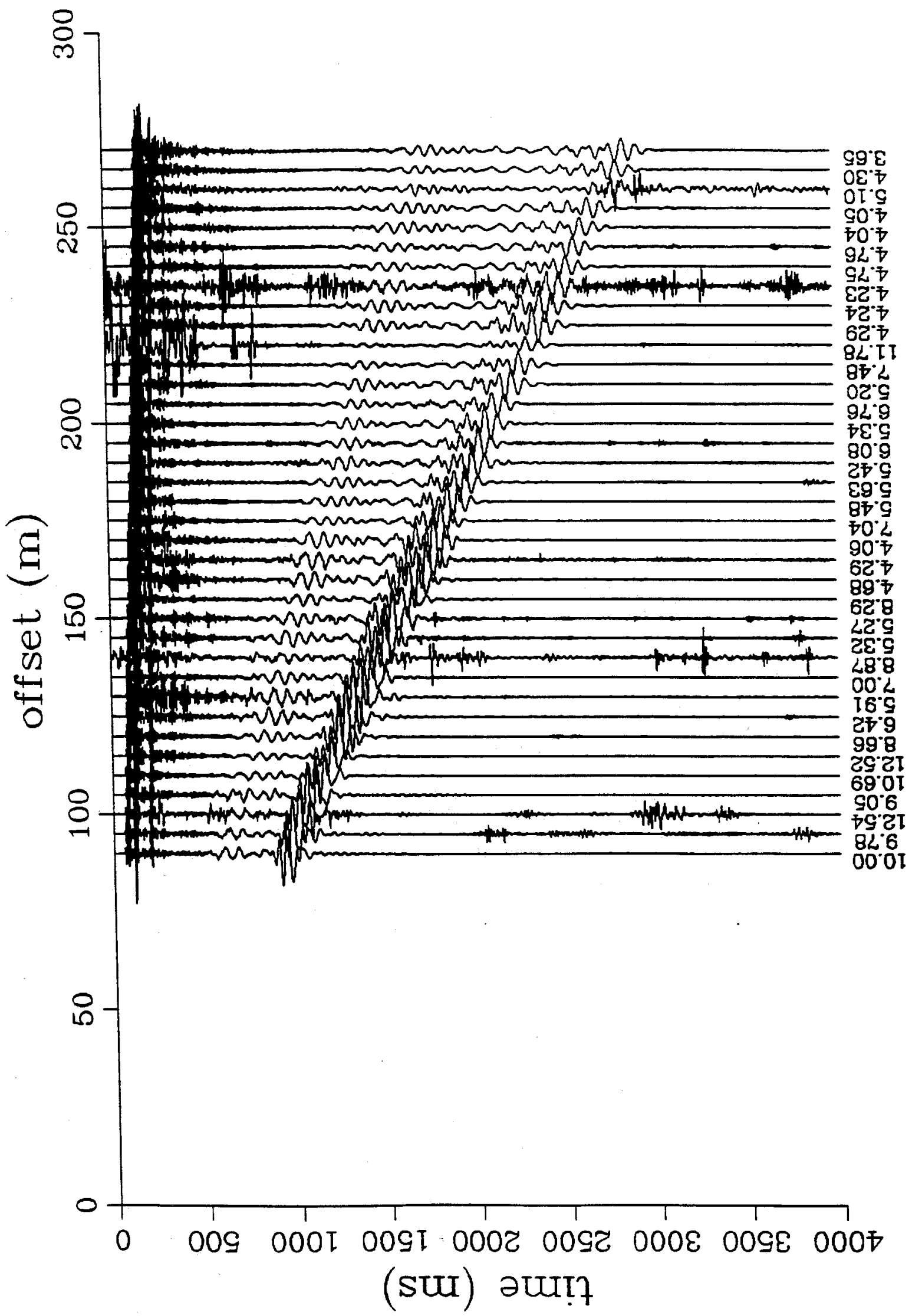


FIGURE C-5B:

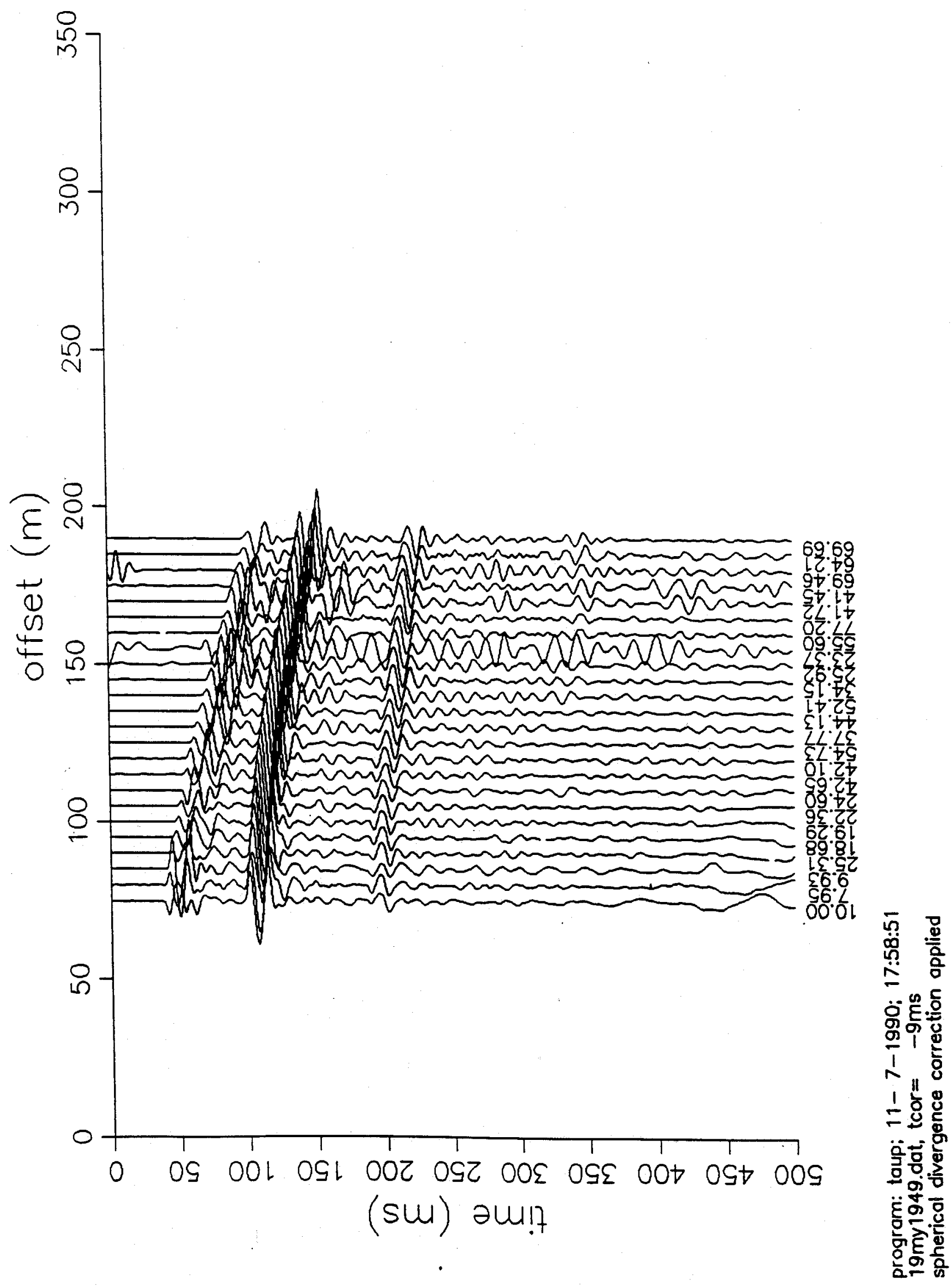

